\title{
Assessment of cognitive flexibility: Reliability and validity studies of Turkish version of the Cognitive Flexibility Inventory
}

\author{
Fatma SAPMAZ* Tayfun DOĞAN **
}

\begin{abstract}
Cognitive Flexibility Inventory (CFI) was developed by Dennis and Wal (2010) in order to measure the cognitive flexibility levels of individuals against the events and circumstances. The purpose of this study is to examine the validity and reliability of Turkish form of CFI 551 university (389 female/162 male) students from Sakarya and Hacettepe Universities participated in the research. The validity of the scale was examined with criterion related validity, exploratory and confirmatory factor analysis methods. The reliability of the scale was examined with Cronbach alpha internal consistency and test-retest methods. The results of factor analysis showed that the scale has a structure of two factors. Cronbach alpha reliability coefficient of CFI was found as .90 for whole of the scale, .90 for "alternatives" sub-dimension and .84 for "control" subdimension. Test-repeat test reliability coefficient of was found as .75 for whole of the scale, .78 for "alternatives" sub-dimension and .73 for "control" sub-dimension. The obtained findings showed that CFI has the sufficient validity and reliability values in measuring the cognitive flexibility levels of Turkish university students.
\end{abstract}

Keywords: Cognitive flexibility, inventory, factor analysis, validity, reliability.

*Assist. Prof. Dr., Sakarya University, Faculty of Education, Depatment of Psychological Counselling and Guidance, Sakarya, Turkey. E-mail: sapmazfatma@gmail.com

${ }^{* *}$ Assist. Prof. Dr., Niğde University, Faculty of Education, Depatment of Psychological Counselling and Guidance, Niğde, Turkey. E-mail: tayfun@tayfundogan.net 


\section{SUMMARY}

Purpose and Significance: The purpose of this study is to examine the validity and reliability of the Turkish version of Cognitive Flexibility Inventory (CFI) developed by Dennis and Wal (2010). CFI was developed to be able to measure the cognitive flexibility levels of individual against the events and circumstances. Defined as being aware of alternative solutions against the circumstances, being flexible against new circumstances and feeling himself /herself competent in such circumstances, cognitive flexibility ranks among the top of concepts which play an important role in many fields from adapting to new circumstances in the complexity of daily life to preserving mental health and developing healthy social relations. For the students who step into a new period in their life entering into the university, university life is a period when face many new circumstances and in which they should exhibit their performances as well as develop new skills. In this context, it can be said that cognitive flexibility levels which reflect their point of views against the circumstances they face may play an important role for them to be able to experience this period as healthy as possible and to deal with the problems they encounter. For this reason, determining the cognitive flexibility levels of university students using a valid and reliable measuring means may direct the content and quality of the consultation services to be offered to them.

Method: The participants of the study consist of the 551 undergraduate students (389 female / 162 male) who studied in Sakarya University Education Faculty and Hacettepe University Faculty of Letters in 2009-2010 term and who were selected with easy sampling method. Cognitive Flexibility Scale (CFI), Optimism Scale (OS) and Boratav Depression Scanning Scale (BORDEPSS) were used as data collecting method in the research. The validity of the scale was examined by criterion related validity, exploratory and confirmatory factor analysis methods. Cronbach alpha internal consistency and test-retest methods were used to test the reliability of the scale.

Results: In linguistic equivalence study, it was found that there is a significant relation $(\mathrm{r}=.97, \mathrm{p}<.001)$ between English form and Turkish form of the scale. As a result of the analysis carried out using principal component analysis and varimax rotation, a two-factor structure with an eigenvalue over 1 which explains the $49.67 \%$ of total variance was obtained. As a result of DFA, it was seen that the two-factor structure was preserved and the fit indexes were in sufficient levels $\left(\chi^{2}=406.98, \mathrm{sd}=167, \chi^{2} / \mathrm{sd}=\right.$ 
2.44, AGFI $=0.90$, GFI $=0.92, \mathrm{NFI}=0.96, \mathrm{RFI}=0.95, \mathrm{CFI}=0.98, \mathrm{IFI}=0.98$, $\mathrm{RMR}=0.052$, $\mathrm{RMSEA}=0.054$ ). Within the scope of criterion related validity, a relation was found between CFI and OS $\quad(\mathrm{r}=.49, \quad \mathrm{p}<.01, \quad \mathrm{n}=95)$, "Control" sub-dimension and OS $(\mathrm{r}=.38, \mathrm{p}<.01)$ and "alternatives" subdimension and $\operatorname{OS}(\mathrm{r}=.45, \mathrm{p}<.01)$. In addition, a relation was found between CFI and CFS ( $\mathrm{r}=.46, \mathrm{p}<.01, \mathrm{n}=95)$, "control" sub-dimension and CFS $(\mathrm{r}=.35$, $\mathrm{p}<.01)$ and "alternatives" sub-dimension and CFS $(\mathrm{r}=.50, \mathrm{p}<.01)$. A relation was found between CFI and BORDEPSS ( $r=-.38, p<.01, n=119)$, "control" sub-dimension $(\mathrm{r}=-.34, \mathrm{p}<.01)$ and "alternatives" sub-dimension $(\mathrm{r}=-.26$, $\mathrm{p}<.01)$. Test-repeat test coefficient CFI was found as .75 for whole of the scale, .78 for "alternatives" sub-dimension and .73 for "control" subdimension in this study. Cronbach alpha internal consistency coefficient of CFI was found as .90 for whole of the scale, .90 for "alternatives" subdimension and .84 for "control" sub-dimension.

Discussion and Conclusions: As a result, it can be said that CFI is a valid and reliable instrument to measure the cognitive flexibility levels of Turkish university students. Psychological counselors and psychotherapists may use CFI when necessary in order to get information about the cognitive flexibility levels of clients. In addition, researchers can study the relations between cognitive flexibility and variables such as psychological disorders, life satisfaction, happiness, psychological health and psychological wellbeing, and can find answers for many questions. 


\title{
Bilişsel Esnekliğin Değerlendirilmesi: Bilişsel Esneklik Envanteri Türkçe Versiyonunun Geçerlik ve Güvenirlik Çalışmaları
}

\author{
Fatma SAPMAZ* Tayfun DOĞAN **
}

ÖZ. Bilişsel Esneklik Envanteri (BEE), bireylerin olaylar ve durumlar karşısındaki bilişsel esneklik düzeylerini ölçebilmek amacıyla Dennis ve Wal (2010) tarafından geliştirilmiştir. Bu çalışmanın amacı BEE' nin Türkçe formunun geçerlik ve güvenirliğini incelemektir. Araştırmaya Sakarya Üniversitesi ve Hacettepe Üniversitesi'nden toplam 551 üniversite öğrencisi (389 kadın/162 erkek) katılmıştır. Ölçeğin geçerliği ölçüt bağıntılı geçerlik, açımlayıcı ve doğrulayıcı faktör analizi yöntemleriyle incelenmiştir. Ölçeğin güvenirliği ise Cronbach alfa içtutarlık ve test-tekrar test yöntemleriyle incelenmiştir. Faktör analizi sonuçları ölçeğin iki faktörlü bir yapıda olduğunu ortaya koymuştur. BEE' nin Cronbach alfa güvenirlik katsayısı ölçeğin bütünü için .90, "alternatifler" alt boyutu için .90 ve "kontrol alt boyutu için .84 olarak bulunmuştur. Test tekrar test güvenirlik katsayısı ise ölçeğin bütünü için .75, "alternatifler" alt boyutu için .78 ve "kontrol alt boyutu için .73 olarak saptanmıştır. Elde edilen bulgular, BEE' nin Türk üniversite öğrencilerinin bilişsel esneklik düzeylerini ölçmede yeterli geçerlilik ve güvenilirlik değerlerine sahip olduğunu göstermiştir.

Anahtar Sözcükler: Bilişsel esneklik, envanter, faktör analizi, geçerlik, güvenirlik.

*Yrd. Doç. Dr., Sakarya Üniversitesi Eğitim Fakültesi Psikolojik Danışmanlık ve Rehberlik Anabilim Dalı Sakarya, Türkiye. E-posta: sapmazfatma@gmail.com

${ }^{* *}$ Yrd. Doç. Dr., Niğde Üniversitesi Eğitim Fakültesi Psikolojik Danışmanlık ve Rehberlik Anabilim Dalı Niğde, Türkiye. E-posta: tayfun@tayfundogan.net 


\section{GíRiș}

Bireyler, diğer insanlarla ilişkilerinde ve günlük yaşantılarında kaçınılmaz şekilde sorunlarla karşılaşmakta, strese maruz kalmakta ve bu zor durumlarla baş etmek için çabalamaktadırlar. Kimi zamanda herhangi bir sorun olmamasına rağmen seçimler yapmak ya da kararlar almak durumunda olabilmektedirler. Karşılaşılan sorunları çözme ya da karar verme durumlarında bireylerin önünde pek çok farklı seçenek bulunabilmektedir. Bireyin genetik özellikleri ve kültürel geçmişi onun herhangi bir durumla ilgili nasıl davranacağı konusunda belirleyici olmaktadır. Yani herhangi bir durum karşısında her birey farklı bir şekilde davranma potansiyeline ve hakkına sahiptir. Bu noktada bilişsel esneklik kavramı ön plana çıkmaktadır. Martin ve Anderson' a (1998) göre bilişsel esneklik, (i) herhangi bir durumla ilgili olarak bireyin alternatif çözüm yollarının ve seçeneklerin farkında olmas1, (ii) yeni durumlara karşı esnek olması ve (iii) bu durumlarda kendisini yetkin olarak hissetmesidir. Bilișsel esnekliğin temelinde alternatiflerin farkında olma ve bu alternatifleri kontrol edebilme konusunda bireyin kendisine güven duyması vardır. Günlük yaşamın karmaşıklığı bireyleri bilişsel açıdan esnek olmaya zorlamaktadır. Bilişsel esnekliğe sahip bireyler insanlarla ilişkilerinde alternatif yolları değerlendirebilmekte ve sosyal durumlara uyum sağlamakta daha başarılı olabilmektedir (Maltby ve ark., 2004; Martin ve Anderson, 1998). Ayrıca bilişsel esneklik düzeyi yüksek bireyler yeteneklerini daha etkili şekilde kullanabilmekte ve karş1laştıkları her problem için birden fazla çözüm yolu olduğunu fark edebilmektedir (Hill 2008). İlgili araştırmalar incelendiğinde bilişsel esneklik, sosyal yeterlik ve kendini ayarlamayla pozitif ilişkili; iletişimde isteksizlik ve katı bir tutum içinde olmayla negatif ilişkili bulunmuştur (Martin, 1995; Martin ve Rubin, 1994). Bilgin (2009), bilişsel esnekliği yordayan değişkenleri incelediği araştırmasında sosyal yetkinlik beklentisinin, otoriter anne-baba tutumunun ve problem çözme becerisinin bilişsel esnekliği anlamlı düzeyde yordadığı sonucuna ulaşmıştır. Araştırmaya göre sosyal yetkinlik beklentisi ve problem çözme becerisi yüksek ergenlerin bilişsel esneklik düzeyleri daha yüksek bulunmuştur. Otoriter anne-baba tutumunun ise bilişsel esnekliği engellediği saptanmıştır.

Depresyonun bilişsel modeline göre çocukluktan itibaren yaşanan deneyimler temel düşünce, varsayım ve inanç sistemlerinin oluşmasına neden olur. $\mathrm{Bu}$ düşünce, varsayım ve inançlar bireyin davranışlarını biçimlendirmede etkili olur. Erken dönemde yaşananlar sonucu oluşan düşünce ve inançlar katı, değişime dirençli ve işlevsellikten uzak olduklarında depresyonun oluşmasına ve devam etmesine neden olur (Sungur, 1994). İşlevsel olmayan türde katı inanç, düşünce ve varsayımlara 
uygun hareket etmek her zaman mümkün olmadığından, kişi zorluk çeker. Diğer yandan ise kişi sürekli olarak işlevsel olmayan düşüncelere göre hareket ettiğinden, düşüncelerinin geçerli olduğuna ilişkin inancı da giderek pekişir. Örneğin "başkalarının dediklerini yaparsam, sevilirim ve değer verilen biri olurum" kuralına inanan bir kişi, sürekli diğerlerinin dediklerini yapar ve elde ettiği olumlu sonuçları buna bağlar, diğer yandan eğer sorun yaşarsa bunu da yeterince diğer insanların dediklerini yapmamaya bağlayarak stratejisini değiştirmeden kullanmaya devam eder (Türkçapar, 2009). Bilişsel terapi modeline göre depresyonun tedavisindeki en etkili yol bireyin kendisine, dünyaya ve geleceğe ilişkin işlevsel olmayan söz konusu kat1 inanç ve düşüncelerini (şema) daha gerçekçi ve işlevsel düşüncelerle değiştirmektir (Beck ve ark., 1979; Young ve ark.. 2001). Bu anlamda bilişsel modelin temel alındığı psikolojik danışma sürecinin en önemli hedeflerinden birisi de danışanlara bilişsel esneklik kazandırmaktır.

Bilişsel Esneklik Envanteri (Cognitive Flexibility Inventory-CFI) Dennis ve Wal (2010) tarafından bireylerin bilişsel esneklik düzeyini değerlendirebilmek amaciyla geliştirilmiş 20 maddelik, yedili likert tipi, özbildirim tarzı bir ölçektir. Ölçek "alternatifler" ve "kontrol" olmak üzere iki boyuttan oluşmaktadır. "Alternatifler" boyutu 13 maddeden oluşmakta ve bireyin zor durumlara alternatif çözümler bulunabileceğine ya da yaşam durumları ve insan davranışlarına yönelik olarak alternatif açıklamaların olabileceğine yönelik maddelerden oluşmaktadır. "Kontrol" alt boyutu ise 7 maddeden oluşmakta ve zor durumların kontrol edilebileceğine yönelik ifadelerden oluşmaktadır. Ölçeğin geliştirilmesi sürecinde iki aşamalı bir yol izlenmiştir. Birinci aşamada 196 üniversite öğrencisi (yaş ortalaması 20.20 ve \% 75'i kadın) araştırmaya katılmıştır ve 50 maddeden oluşan CFI'nın ilk halini ve diğer ölçme araçlarını uygulamışlardır. İkinci aşamada, 7 hafta sonra 196 kişilik bu öğrenci grubu tekrar davet edilmiş ancak 152 kişi aynı ölçekleri tekrar uygulamıştır. Hem birinci hem de ikinci uygulamadan elde edilen verilerle yapılan açımlayıcı faktör analizi (AFA) sonucu faktör yükleri .52 ile 84 arası değişen toplam varyansın \% 39' unu açıklayan iki faktörlü bir yapı elde edilmiştir. CFI' nın güvenirliği Cronbach alfa iç tutarlık ve test tekrar test yöntemleri kullanılarak incelenmiştir. Buna göre ölçeğin bütünü için Cronbach alfa iç tutarlık katsayısı birinci uygulama için .90 ve ikinci uygulama için .91 olarak bulunmuştur. "Alternatifler" alt boyutu için birinci ve ikinci uygulamada iç tutarlık katsayısı .91 olarak bulunmuştur. İkinci alt boyut olan "kontrol" alt boyutu için ise ilk uygulamada iç tutarlık katsayısı .86 ve ikinci uygulamada .84 olarak bulunmuştur. CFI' nın bütünü ile "alternatifler" alt boyutu arasinda birinci uygulamada $(\mathrm{r}=.89, \mathrm{p}<.001)$ ve ikinci uygulamada $(\mathrm{r}=.90, \mathrm{p}<.001)$ istatistiksel olarak anlamlı ilişki bulunmuştur. CFI' nın bütünü ile "kontrol" alt boyutu arasında ise birinci 
uygulamada $(r=79, p<.001)$ ve ikinci uygulamada $(r=80, p<001)$ istatistiksel olarak anlamlı ilişki bulunmuştur. Alt boyutlar arasında ise birinci uygulamada $(\mathrm{r}=41, \mathrm{p}<.001)$, ikinci uygulamada $(\mathrm{r}=45, \mathrm{p}<.001)$ istatistiksel olarak anlamlı ilişki bulunmuştur. 7 hafta arayla yapılan iki uygulama sonucu elde edilen test tekrar test güvenirlik katsayısı ölçeğin bütünü için $(\mathrm{r}=.81, \mathrm{p}<001)$; "alternatifler" alt boyutu için $(\mathrm{r}=.75, \mathrm{p}<.001)$ ve "kontrol" alt boyutu için $(\mathrm{r}=.77, \mathrm{p}<001)$ olarak saptanmıştır.

Bu çalışmanım temel amacı Bilişsel Esneklik Envanteri'nin (BEE) Türk üniversite öğrencilerinden oluşan örneklemde geçerlik ve güvenirliğini incelemektir.

\section{YÖNTEM}

\section{Araștırmanın Katılımcıları}

BEE' nin Türkçe uyarlaması için yürütülen çalışmanın katılımcılarını, 2009-2010 eğitim-öğretim y1lında Sakarya Üniversitesi Eğitim Fakültesi ve Hacettepe Üniversitesi Edebiyat Fakültesinde öğrenim gören 551 üniversite öğrencisi oluşturmaktadır (389 kadın / 162 erkek). Katılımcıların yaşları 17 ile 28 arasında değişmektedir ve yaş ortalaması 20.04' tür ( $\mathrm{S}=1.79)$.

\section{Veri Toplama Araçları}

\section{Bilişsel Esneklik Ölçeği (BEÖ)}

Araştırmada kullanılan Bilişsel Esneklik Ölçeği, Bilgin (2009) tarafindan geliştirilmiştir. Ölçek 19 maddeden oluşmaktadır. BEÖ’ nün ölçüt bağıntılı geçerliği Fonksiyonel Olmayan Tutumlar Ölçeği kullanılarak yapılmış ve iki ölçek arasındaki korelasyon .-44 olarak saptanmıştır. BEÖ' nün Cronbach alfa iç tutarlık katsayısı .92 ve test tekrar test yöntemiyle elde edilen güvenirlik katsayıs1 .77 olarak rapor edilmiştir. Madde toplam korelasyonlarının ise .49 ile .63 arasında değişen değerlerde olduğu bildirilmiştir.

\section{İyimserlik Ölçeği (İÖ)}

İyimserlik Ölçeği (IÖ), Balcı ve Yılmaz (2002) tarafından bireylerin iyimserlik düzeylerini ölçebilmek amacıyla geliştirilmiş 24 maddeli, 4' lü Likert tipi, özbildirim tarzı bir ölçektir. Ölçeğin iç tutarlığını belirlemeye yönelik olarak hesaplanan Cronbach Alpha iç tutarlık katsayıs1 .96 olarak ve test tekrar test yöntemiyle elde edilen güvenirlik katsayıs1 .61 olarak bulunmuştur. 


\section{Boratav Depresyon Tarama Ölçeği (BORDEPTA)}

Boratav Depresyon Tarama Ölçeği, epidemiyolojik çalışmalarda ve birinci basamak sağlık hizmetlerinde depresyonu tanımaya ve taramaya yönelik olarak Boratav (2003) tarafından geliştirilmiş 16 maddelik, evethayır şeklinde cevaplanabilen bir ölçme aracıdır. Ölçeğin Cronbach alfa iç tutarlık katsayısı .90 olarak bulunmuştur. Benzer ölçek geçerliği kapsamında BORDEPTA ile Beck Depresyon Ölçeği arasında .81, Sürekli Kaygı Envanteri ile .76 korelasyon bulunmuştur.

\section{İşlemler}

Araştırmada ilk olarak John P. Dennis ile e-mail yoluyla iletişime geçilerek ölçeğin uyarlanması için gerekli izinler alınmıştır. İkinci aşamada ölçek özgün dili olan İngilizce' den Türkçe'ye çevrilmiştir. Ölçek uyarlama çalışmalarında dilsel eşdeğerlik büyük önem taşımaktadır. Bir kültürde geliştirilmiş̧ ölçeğin başka bir dile çevrilmesi doğal olarak ölçeğin doğasını değiştirir. $\mathrm{Bu}$ kaçınılmaz değişim anlatım ve kavramlaştırma farklılıklarından kaynaklanır. Farklılıkların en aza indirilmesi için çeviri işlemi titizlikle yapılmalı ve özgün formla yeni formun dilsel eşdeğerlik açısından yeterli değerlere sahip olduğundan emin olunmalıdır (Öner, 1997; Şeker ve Gençdoğan, 2006). Ölçeğin özgün formu yedi basamaklı Likert tipi bir ölçektir. Türkçe anlam ve anlaşılırlık açısından beşten fazla seçenek yazılması güçlüğe neden olmaktadır. Yani seçenekler anlam olarak birbirine çok yakın olmakta ve cevaplayıcıların bu seçenekleri ayırt etmesi oldukça zor olmaktadır. Örneğin, 'bazen', 'ara sıra', 'seyrek', 'nadiren', 'çok az' gibi seçenekleri birbirinden ayırt etmek oldukça güçtür (Şeker ve Gençdoğan, 2006). Bundan dolayı ölçeğin Türkçe formu beşli Likert tipine göre hazırlanmıştır. Uygulamalar ders saatlerinde yapılmış; araştırma ve ölçeğin uygulanması ile ilgili gerekli bilgiler verildikten sonra gönüllü olanların araştırmaya katılmaları istenmiştir. Uygulama 10-15 dakika kadar sürmüştür. $\mathrm{Bu}$ aşamadan sonra verilerin faktör analizine uygun olup olmadığ incelenmiş ve uygun olduğuna karar verilerek faktör analizine geçilmiştir. $\mathrm{Bu}$ çalışmada ölçeğin Türk üniversite öğrencilerinden oluşan örneklemde nasıl bir faktör yapısına sahip olduğunu ortaya koymak üzere açımlayıcı faktör analizi yapılmıştır. BEE' nin özgün formuna ait faktör yapısının Türk üniversite öğrencilerinden oluşan örneklemde doğrulanıp doğrulanmayacağını belirlemek üzere ise doğrulayıcı faktör analizi yapılmıştır. Ölçüt bağıntılı geçerlik kapsamında BEE ile birlikte Boratav Depresyon Ölçeği, İyimserlik Ölçeği ve Bilişsel Esneklik Ölçeği uygulanmış, benzer ölçek geçerliği incelenmiştir. Ölçeğin güvenirliği ise 
Cronbach alfa iç tutarlık ve test tekrar test güvenirlik yöntemleriyle incelenmiştir. Ayrıca BEE' den alınan puanların cinsiyete göre farklılaşıp farklılaşmadığ da incelenmiştir. Elde edilen bulgular tartışılmış ve önerilerde bulunulmuştur. Verilerin analizi SPSS 11.5 ve Lisrel 8.51 programları vasıtasıyla yapılmıştır.

\section{BULGULAR}

\section{Dilsel Eşdeğerlik}

Ölçek uyarlama çalışmalarının ilk aşamasını orijinal ölçeğin hedef dile tercüme edilmesi oluşturmaktadır. İlk aşamada özgün ölçek kaynak dil olan İngilizce' den hedef dil olan Türkçe' ye araştırmacı, psikolojik danışma alanından bir akademisyen ve iki çevirmen tarafından ayrı ayrı çevrilmiş ve çeviriler incelenerek özgün formdaki maddeleri en iyi temsil ettiği düşünülen ifadeler benimsenmiştir. İkinci aşamada ise ölçeğin özgün formu ve çeviri formu Hacettepe üniversitesi Amerikan Kültürü ve Edebiyatı Bölümünde öğrenim gören her iki dile de iyi derecede hakim 42 öğrenciye uygulanmış, toplam puan ve her bir madde açısından iki uygulama arasındaki ilişki incelenmiştir. Dilsel eşdeğerlik için yapılan korelasyon analizi sonucunda, ölçeğin İngilizce formu ile Türkçe formu arasında pozitif yönde istatistiksel olarak anlamlı bir ilişki $(\mathrm{r}=.97, \mathrm{p}<.001)$ olduğu görülmüştür. Elde edilen bulgular Tablo 1' de sunulmuştur.

Tablo 1. Ingilizce ve Türkçe formdaki maddeler arasindaki ilişki düzeyleri

\begin{tabular}{cccc}
\hline Maddeler & $\boldsymbol{r}$ & Maddeler & $\boldsymbol{r}$ \\
\hline Madde1 & $.48^{* *}$ & Madde11 & $.77^{* *}$ \\
Madde2 & $.71^{* *}$ & Madde12 & $.92^{* *}$ \\
Madde3 & $.85^{* *}$ & Madde13 & $.85^{* *}$ \\
Madde4 & $.84^{* *}$ & Madde14 & $.78^{* *}$ \\
Madde5 & $.95^{* *}$ & Madde15 & $.65^{* *}$ \\
Madde6 & $.75^{* *}$ & Madde16 & $.84^{* *}$ \\
Madde7 & $.70^{* *}$ & Madde17 & $.69^{* *}$ \\
Madde8 & $.90^{* *}$ & Madde18 & $.88^{* *}$ \\
Madde9 & $.74 * *$ & Madde19 & $.82^{* *}$ \\
Madde 10 & $.93^{* *}$ & Madde20 & $.87 * *$ \\
\hline$* * p<.001$ & & &
\end{tabular}




\section{Yapı Geçerliği}

Açımlayıcı Faktör Analizi (AFA): BEE' nin faktör yapısını ortaya koymak üzere AFA yapılmıştır. Öncelikle verilerin faktör analizine uygunluğunu belirlemek amaciyla örneklem uygunluğu (sampling adequacy) ve Barlett Sphericity testleri yapılmıştır. Kaiser-Meyer-Olkin (KMO) örneklem uygunluk katsayısı 0.92 ve Barlet-Sphericity testi ki kare değeri 3892.36 ( $\mathrm{p}<.001)$ olarak bulunmuştur. Literatür incelendiğinde faktör analizi için KMO değerinin .60' dan yüksek olması ve Barlett Spehericity testinin de anlamlı çıkması gerektiği belirtilmektedir (Büyüköztürk, 2004). Buna göre, elde edilen sonuçlar, verilerin faktör analizi için uygun olduğunu göstermektedir. Temel bileşenler yöntemi ile varimaks döndürme kullanılarak, özgün formda olduğu gibi iki faktörle sınırlandırılarak yapılan analiz sonucunda, özdeğeri 1 'in üzerinde olan ve toplam varyansın \% 49.67' sini açıklayan iki faktörlü bir yapı elde edilmiştir. Ölçekte bulunan tüm maddelerin faktör yükleri .30 ve üzerinde olduğundan dolayı ölçekten hiçbir maddenin çıkarılmasına gerek duyulmamıştır. "Alternatifler" alt boyutuna ilişkin faktör yükleri $.44-.80$ arasında değişmekte ve bu alt boyut toplam varyansın \% 36.18' ini açıklamaktadır. "Kontrol" alt boyutuna ilişkin faktör yükleri ise $.59-.84$ arasında değişmekte ve bu alt boyutta toplam varyansın \% 13.49' unu açıklamaktadır. Özgün formda "kontrol" alt boyutunda yer alan 15. Madde bu çalışmada "alternatifler" alt boyutunda yer almıştır. Ancak söz konusu madde anlam ve ifade açısından incelendiğinde "kontrol" alt boyutunda yer almasının uygun olacağı kanaatine varılmıştır. Doğrulayıcı faktör analizinde bu madde özgün formunda yer aldığı alt boyutta işleme alınmıştır. BEE' nin toplam puanı ile "kontrol" alt boyutu arasında $(\mathrm{r}=.78$, $\mathrm{p}<.001)$, "alternatifler" alt boyutu arasinda ise $(\mathrm{r}=.90, \mathrm{p}<.001)$ korelasyon bulunmuştur. BEE' nin alt boyutları arasındaki korelasyon katsayısı da ( $\mathrm{r}=$ $.42, \mathrm{p}<.001$ ) olarak bulunmuştur. AFA sonucu elde edilen bulgular Tablo 2' de ayrıntılı olarak verilmiştir. 
Tablo 2. Açımlayıcı faktör analizi sonuçları

\begin{tabular}{|c|c|c|}
\hline Maddeler & F1 & F2 \\
\hline 1. Olay ve durumları değerlendirmede iyiyimdir. & .44 & \\
\hline $\begin{array}{l}\text { 3. Bir konuda karar vermeden önce birçok seçeneği göz önünde } \\
\text { bulundururum. }\end{array}$ & .66 & \\
\hline 5. Zor durumlara pek çok farklı açılardan bakmak hoşuma gider. & .57 & \\
\hline $\begin{array}{l}\text { 6. Bir davranışın nedenleri konusunda karara varmadan önce ek bilgiler } \\
\text { ararım. }\end{array}$ & .66 & \\
\hline 8. Olayları karşımdaki kişilerin bakış açılarından da görmeye çalışırım. & .62 & \\
\hline 10. Kendimi diğer insanların yerine koyarak onları anlamada iyiyimdir. & .55 & \\
\hline 12. Zor durumlara değişik açılardan bakmak önemlidir. & .60 & \\
\hline $\begin{array}{l}\text { 13. Bir zorlukla karşılaştı̆̆ımda nasıl davranacağımla ilgili olarak pek çok } \\
\text { seçeneği göz önünde bulundururum. }\end{array}$ & .78 & \\
\hline 14. Herhangi bir duruma çoğu kez farklı açılardan bakarım. & .80 & \\
\hline $\begin{array}{l}\text { 16. Davranışların nedenlerini anlamaya çalışırken bütün olası gerçekleri ve } \\
\text { bilgileri göz önünde bulundururum. }\end{array}$ & .73 & \\
\hline $\begin{array}{l}\text { 18. Zor bir durumla karşılaştığımda durur ve çözüm için çeşitli yollar } \\
\text { düşünürüm. }\end{array}$ & .72 & \\
\hline $\begin{array}{l}\text { 19. Bir sorunla karşılaştığım zaman sorunu çözebilmek için birden fazla yol } \\
\text { olduğunu düşünürüm. }\end{array}$ & .70 & \\
\hline $\begin{array}{l}\text { 20. Zor durumlarla ilgili harekete geçmeden önce pek çok seçeneği } \\
\text { değerlendiririm. }\end{array}$ & .78 & \\
\hline 2. Zor durumlarla karşı karşıya kaldığımda karar vermekte güçlük çekerim.* & & .71 \\
\hline $\begin{array}{l}\text { 4. Zor durumlarla karşılaştığım zaman, kontrolümü kaybediyor gibi } \\
\text { hissederim.* }\end{array}$ & & .75 \\
\hline $\begin{array}{l}\text { 7. Zor durumlarla karşılaştı̆̆ımda o kadar stresli olurum ki, sorunu nasıl } \\
\text { çözeceğimi düşünemem.* }\end{array}$ & & .78 \\
\hline $\begin{array}{l}\text { 9. Zor durumlarla baş edebilmek için önümde farklı birçok seçeneğin olması } \\
\text { benim için sıkıntı vericidir.* }\end{array}$ & & .59 \\
\hline 11. Zor durumlarla karşılaştığımda tam olarak ne yapacağımı bilemem.* & & .84 \\
\hline 15. Yaşamda karşılaştı̆̆ım güçlüklerle baş etmede yetenekliyim. & .45 & \\
\hline $\begin{array}{l}\text { 17. Zor durumlarda bir şeyleri değiştirme konusunda kendimi güçsüz } \\
\text { hissederim.* }\end{array}$ & & .76 \\
\hline Açıklanan Varyans (\%) & 36.18 & 13.49 \\
\hline 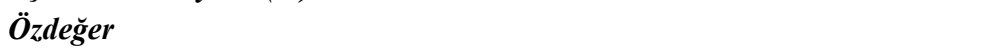 & 7.24 & 2.70 \\
\hline
\end{tabular}

*Bu maddeler tersten kodlanmaktadır. 


\section{Doğrulayıcı Faktör Analizi (DFA)}

BEE' nin özgün formunun faktör yapısının, Türk üniversite öğrencilerinden oluşan örneklemde doğrulanıp doğrulanmayacağını sınamak amacıyla DFA yapılmıştır. DFA' da sınanan modelin yeterli derecede uyum gösterip göstermediğini ortaya koymak üzere birçok uyum indeksi kullanılmaktadır. Bu çalışmada yapılan DFA için, Ki-Kare Uyum Testi (Chi-Square Goodness), İyilik Uyum İndeksi (Goodness of Fit Index-GFI), Düzeltilmiş Uyum İndeksi (Adjusted Goodness of Fit Index-AGFI), Karşılaştırmalı Uyum İndeksi (Comparative Fit Index-CFI), Normlaştırılmış Uyum İndeksi (Normed Fit Index-NFI), Göreli Uyum İndeksi (Relative Fit Index-RFI), Fazlalık Uyum Indeksi (Incremental Fit Index-IFI), Ortalama Hataların Karekökü (Root Mean Square Residuals-RMR), Yaklaşık Hataların Ortalama Karekökü (Root Mean Square Error of ApproximationRMSA) uyum indeksleri incelenmiştir. İlgili literatür incelendiğinde GFI, CFI, NFI, RFI, IFI ve AGFI uyum indeksleri için kabul edilebilir uyum değeri 0.90 ve mükemmel uyum değeri 0.95 olarak kabul edilmektedir (Bentler, 1980; Marsh ve ark., 2006). RMSEA için ise 0.08 kabul edilebilir uyum değeri, 0.05 mükemmel uyum değeri olarak kabul edilmektedir (Brown ve Cudeck, 1993; Byrne ve Campbell, 1999). Modelin uygunluğu ile ilgili olarak ki kare değerinin serbestlik derecesine oranının 5'ten küçük olmas1 gerekmektedir (Kline, 2005; Meyers, Gamst ve Guarion, 2006). Bu araştırmada model için ki kare değerinin serbestlik derecesine oranı (406.98/167) 2.44 olarak bulunmuştur. DFA' da modele ait parametre tahminlerinin tümünün pozitif yönde yüklendiği sonucuna ulaşılmıştır (Bkz. Şekil 1). Parametre tahminleri "alternatifler" alt boyutu için .45-.81 arasında değişmektedir. "Kontrol" alt boyutu için ise parametre tahminleri, .41-.77 arasında değişen değerlerde bulunmuştur. DFA sonucu, tüm uyum indekslerinin yeterli düzeyde uyum gösterdiği sonucuna ulaşılmıştır. Elde edilen uyum indeksi değerleri Tablo 3' de verilmiştir. 


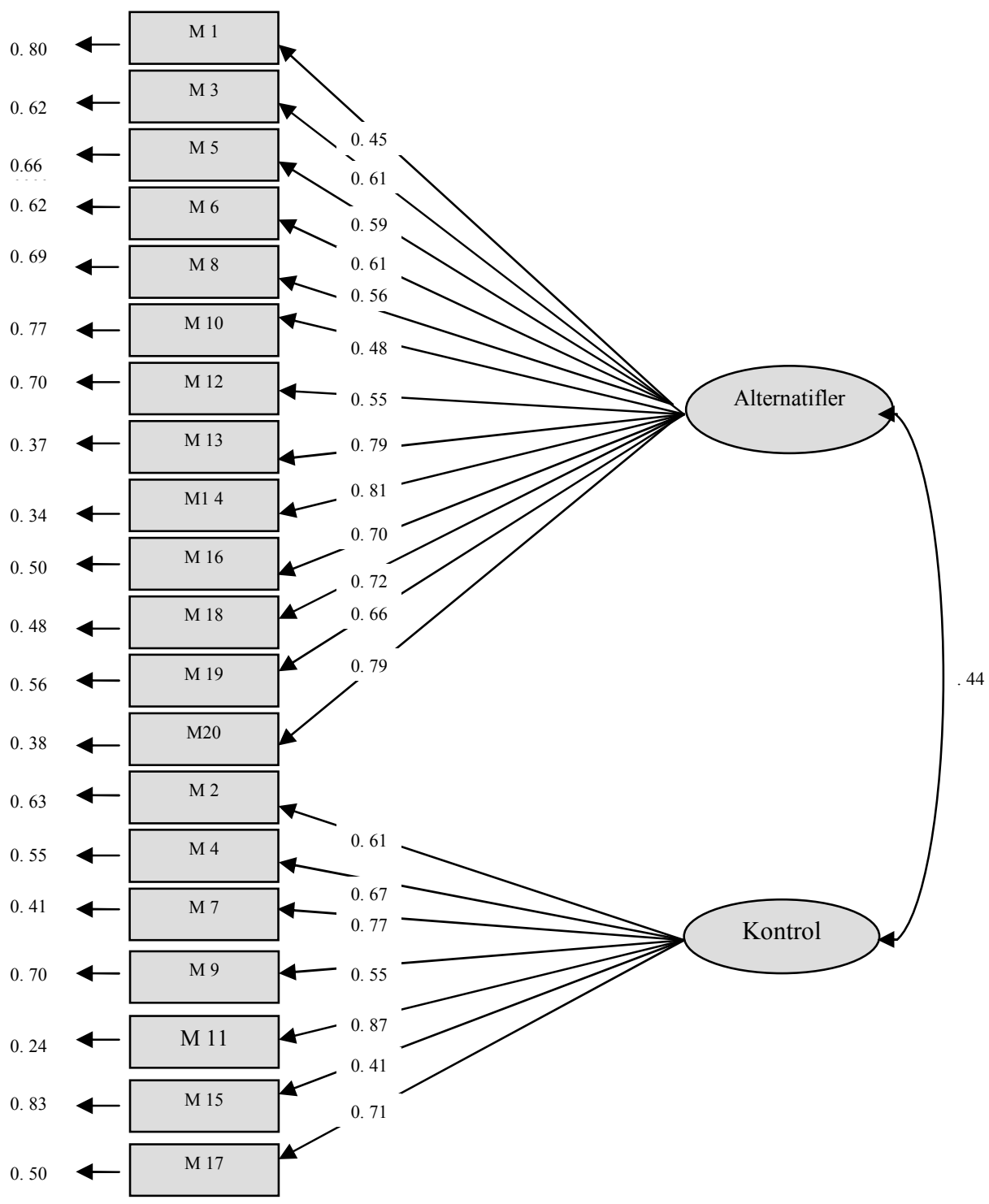

Şekil 1. BEE' ye ilişkin Path Diyagramı ve faktör yükleri

Tablo 3. DFA modelinin uyum iyiliği indeksleri

\begin{tabular}{ccccccccccc}
\hline$\chi^{2}$ & sd & $\chi^{2} / \mathbf{s d}$ & AGFI & GFI & NFI & RFI & CFI & IFI & RMR & RMSEA \\
406.98 & 167 & 2.44 & 0.90 & 0.92 & 0.96 & 0.95 & 0.98 & 0.98 & 0.052 & 0.054 \\
\hline
\end{tabular}




\section{Ölçüt Bağıntılı Geçerlik}

Ölçüt bağıntılı geçerlik kapsamında BEE ile Boratav Depresyon Tarama Ölçeği- BORDEPTA (Boratav, 2003), Bilişsel Esneklik Ölçeği-BEÖ (Bilgin, 2009) ve İyimserlik Ölçeği-İÖ (Balcı ve Yılmaz, 2002) arasındaki ilişsiler incelenmiştir. Teorik olarak, BEE ile BORDEPTA arasında negatif yönde bir ilişki olması beklenmiştir. BEE ile İÖ ve BEÖ arasında ise pozitif yönde bir ilişki olması beklenmiştir. BEE ile İÖ arasında $(\mathrm{r}=.49, \mathrm{p}<.01$, $\mathrm{n}=95)$, "Kontrol" alt boyutuyla İÖ arasında $(\mathrm{r}=.38, \mathrm{p}<.01)$ ve "alternatifler" alt boyutuyla İÖ arasında $(\mathrm{r}=.45, \mathrm{p}<.01)$ ilişki bulunmuştur. BEE ile BEÖ arasinda $(\mathrm{r}=.46, \mathrm{p}<.01, \mathrm{n}=95)$, "kontrol" alt boyutuyla BEÖ arasinda $(\mathrm{r}=.35$, $\mathrm{p}<.01)$ ve "alternatifler" alt boyutuyla BEÖ arasında $(\mathrm{r}=.50, \mathrm{p}<.01)$ ilişki bulunmuştur. BEE ile BORDEPTA arasinda ise $(\mathrm{r}=-.38, \mathrm{p}<.01, \mathrm{n}=119)$, "kontrol" alt boyutuyla $(\mathrm{r}=-.34, \mathrm{p}<.01)$ ve "alternatifler" alt boyutuyla $(\mathrm{r}=$ $.26, \mathrm{p}<.01)$ ilişki bulunmuştur.

Tablo 4. Ölçüt bağıntıll geçerliğe ilişkin korelasyon katsayıları

\begin{tabular}{lccc}
\hline & İÖ & BEÖ & BORDEPTA \\
\hline BEE Toplam & $.49^{* *}$ & $.46^{* *}$ & $-.38^{* *}$ \\
Kontrol Alt Boyutu & $.38^{* *}$ & $.35^{* *}$ & $-.33^{* *}$ \\
Alternatifler Alt Boyutu & $.44^{* *}$ & $.50^{* *}$ & $-.26^{* *}$ \\
\hline
\end{tabular}

**p<.001, BEE: Bilişsel Esneklik Envanteri; İÖ: İyimserlik Ölçeği; BORDEPTA: Boratav Depresyon Ölçeği; BEÖ: Bilişsel Esneklik Ölçeği

\section{Güvenirlik}

$\mathrm{Bu}$ çalışmada $\mathrm{BEE}$ ' nin güvenirliğini ortaya koymak üzere test tekrar test ve Cronbach alfa iç tutarlık yöntemleri kullanılmıştır. 70 üniversite ögrencisine iki hafta arayla uygulama sonucu elde edilen test tekrar test korelasyon katsayısı ölçeğin bütünü için . 75, "alternatifler" alt boyutu için .78 ve "kontrol" alt boyutu için . 73 olarak bulunmuştur. BEE' nin Cronbach alfa iç tutarlık katsayısı ise ölçeğin bütünü için .90, "alternatifler" alt boyutu için .90 ve "kontrol" alt boyutu için .84 olarak bulunmuştur. Güvenirlik analizlerine yönelik olarak elde edilen bu sonuçlar BEE' nin yeterli düzeyde güvenilir bir ölçme aracı olduğunu göstermektedir. 
Tablo 5. Bilişsel Esneklik Ölçeği ve alt boyutlarına ilişskin Test-Tekrar Test güvenirlik katsaylları

\begin{tabular}{llcccc}
\hline Faktör & Uygulama & $\mathbf{N}$ & $\overline{\mathrm{X}}$ & $\mathbf{S s}$ & Test-tekrar test \\
\hline \multirow{2}{*}{ Alternatifler } & Birinci uygulama & 70 & 25.23 & 6.26 & $.78^{* *}$ \\
& İkinci uygulama & 70 & 25.90 & 7.16 & \\
\cline { 2 - 6 } Kontrol & Birinci uygulama & 70 & 22.87 & 4.90 & \multirow{2}{*}{$.73^{* *}$} \\
& İkinci uygulama & 70 & 22.93 & 4.39 & \\
\cline { 2 - 6 } Ölçeğin Tümü & Birinci uygulama & 70 & 48.20 & 6.09 & \multirow{2}{*}{$.75^{* *}$} \\
& İkinci uygulama & 70 & 48.83 & 6.84 & \\
\hline$* * \mathrm{p}<001$ & & & & &
\end{tabular}

\section{BEE'nin Cinsiyete Göre Farklılığının İncelenmesi}

BEE'ye ait puanların cinsiyete ilişkin olarak farklılıklaşıp farklılaşmadığı, bağımsız örneklemler için t-test analizi kullanılarak incelenmiştir. Buna göre "alternatifler" alt boyutu puanları $(\operatorname{kad} ı n \overline{\mathrm{x}}=51.92$, erkek $\overline{\mathrm{X}}=52.70, t_{0.05: 437}=.938, \quad p=.318$ ) açısından cinsiyete göre .05 düzeyinde istatistiksel olarak anlamlı bir farklılık bulunmamıştır. "Kontrol" alt boyutu puanları $\left(\operatorname{kad} \ln \overline{\mathrm{x}}=22.89\right.$, erkek $\overline{\mathrm{x}}=25.47, t_{0.05: 437}=4.72, \quad p=$ .000) açısından kadınların puanlarının erkeklere göre istatistiksel olarak anlamlı düzeyde yüksek olduğu sonucuna ulaşılmıştır. BEE' den alınan toplam puanlar açısından ise $\left(\operatorname{kad} \ln \overline{\mathrm{X}}=74.82\right.$, erkek $\overline{\mathrm{X}}=78.17, t_{0.05: 437}=$ 2.89, $p=.003$ ) erkeklerin bilişsel esneklik düzeylerinin kadınlarınkinden anlamlı düzeyde yüksek olduğu görülmüştür. Elde edilen sonuçlar Tablo 6'da sunulmuştur.

Tablo 6. BEE' de cinsiyete ilişkin farklllıklara ait bağımsız örneklemler için t-testi

\begin{tabular}{llcccccc}
\hline & Cinsiyet & $\boldsymbol{N}$ & $\overline{\mathrm{X}}$ & Ss & $\boldsymbol{t}$ & sd & $\boldsymbol{p}$ \\
\hline \multirow{2}{*}{ Alternatifler } & Kadın & 318 & 51.92 & 6.97 & \multirow{2}{*}{.938} & 437 & $.318^{*}$ \\
& Erkek & 121 & 52.70 & 8.05 & & & \\
\cline { 2 - 8 } Kontrol & Kadın & 318 & 22.89 & 5.17 & \multirow{2}{*}{4.72} & 437 & $.000^{*}$ \\
& Erkek & 121 & 25.47 & 4.92 & & & \\
\cline { 2 - 8 } $\begin{array}{l}\text { Ölçeğin } \\
\text { Tümüi }\end{array}$ & Kadın & 318 & 74.82 & 10.13 & \multirow{2}{*}{2.89} & 437 & $.003^{*}$ \\
\hline
\end{tabular}

$* \mathrm{p}<.05$ 


\section{Ölçeğin Puanlanması}

BEE, 5' li likert tipinde bir ölçektir. "Hiç uygun değil" (1), "Uygun Değil" (2), "Biraz Uygun" (3), "Uygun" (4), "Tamamen Uygun" (5) şeklinde puanlanmaktır. Ölçeğin 2, 4, 7, 9, 11, 17. maddeler tersten kodlanmaktadır. Ölçekten toplam bilişsel esneklik puanı, "alternatifler" alt boyutu puanı ve "kontrol" alt boyutu puanı olmak üzere üç farklı türde puan alınabilmektedir. Puanların yüksekliği bilişsel esnekliğin yüksek olduğuna işaret etmektedir. Bilişsel esnekliği yüksek bireylerin özellikleri, kendi başına karar alabilme becerisi ve benlik saygısı yüksek, olaylara farklı açılardan bakabilen, içten denetimli, depresif düzeyi daha düşük ve iyimser olarak siralanabilir.

\section{TARTIŞMA}

Bu çalışmada, Bilişsel Esneklik Envanteri (BEE)'nin Türk üniversite öğrencilerinden oluşan örneklemde psikometrik özelliklerinin incelenmesi amaçlanmıştır. Araştırmada ilk olarak ölçeğin İngilizce olan özgün formu Türkçe' ye çevrilmiş ve dilsel eşdeğerlik çalışması yapılmıştır. Dilsel eşdeğerlik çalışmasında, ölçeğin özgün formu ile Türkçe formunun yeterli düzeyde ilişkili olduğu sonucuna ulaşıldıktan sonra, geçerlik ve güvenirlik çalışmalarına geçilmiştir. Bu kapsamda geçerlik çalışmaları olarak yapı geçerliği ve ölçüt bağıntılı geçerlik çalışmaları yapılmıştır. Ölçeğin güvenirliğini ortaya koymak üzere ise Cronbach alfa iç tutarlık ve test-tekrar test yöntemleri kullanılmıştır. Ayrıca, BEE puanlarının cinsiyete göre farklılaşıp farklılaşmadığını ortaya koymak amacıyla da bağımsız örneklemler $t$ testi yapılmıştır. Geçerlik ve güvenirliğe ilişkin olarak elde edilen bulgular, Dennis ve Wal (2010) tarafindan gerçekleştirilen araştırma sonuçlarıyla karşılaştırıldığında büyük oranda benzerlik görülmektedir.

Ölçek uyarlama çalışmalarında uyarlaması yapılacak ölçeğin kaynak dilden hedef dile çevirisi ve dilsel eşdeğerliği büyük önem taşımaktadır. Toplam puan açısından özgün form ile Türkçe form arasında .97 korelasyon elde edilmiştir. Bu sonuçlar dilsel eşdeğerlik açısından Türkçe ve İngilizce formun yüksek düzeyde uyumlu olduğunu göstermektedir.

BEE' nin yapı geçerliğini ortaya koymak üzere doğrulayıcı (DFA) ve açımlayıcı faktör analizi (AFA) yapılmıştır. Ölçeğin Türk örneklemde nasıl bir faktör yapısına sahip olduğunu ortaya koymak üzere yapılan AFA sonucu özdeğeri 1' in üzerinde olan toplam varyansın \% 49.67' sini açıklayan iki faktörlü bir yapı elde edilmiştir. "Alternatifler" alt boyutu için faktör yükleri $.49-.81$ arasında, "kontrol" alt boyutu için ise .43 ile .86 arasında değişmektedir. 15. madde hariç tüm maddelerin özgün formda yer alan 
faktörlerde yüklendiği görülmüştür. 15. madde ise her iki faktörde de yakın değerler almıştır. Ancak söz konusu madde anlam ve ifade açısından incelenerek "kontrol" alt boyutunda yer almasının doğru olacağına kanaat getirilmiştir. Ölçeğin özgün formunun faktör yapısının Türk üniversite öğrencilerinden oluşan örneklemde doğrulanıp doğrulanmayacağını sınamak üzere DFA yapılmıştır. DFA sonucu elde edilen uyum indeksi değerlerinin oldukça yüksek olduğu gözlemlenmiş ve özgün formun faktör yapısını doğruladığı sonucuna ulaşılmıştır.

BEE' nin ölçüt bağıntılı geçerliğini ortaya koymak üzere İyimserlik Ölçeği (İÖ), Boratav Depresyon Tarama Ölçeği (BORDEPTA) ve Bilişsel Esneklik Ölçeği (BEÖ) kullanılmıştır. Teorik olarak BEE ile İÖ ve BEÖ arasında pozitif, BORDEPTA ile ise negatif bir ilişki olması beklenmiştir. Beklendiği üzere elde edilen sonuçlar, toplam puan ve alt boyutları açısından BEE ile İÖ ve BEÖ arasında pozitif yönde istatistiksel olarak anlamlı ilişkiler olduğunu ortaya koymuştur. BEE ve alt boyutlarıyla BORDEPTA arasında ise negatif yönde anlamlı ilişkiler elde edilmiştir.

BEE' nin güvenirliğini ortaya koymak üzere iki hafta ara ile 70 üniversite öğrencisine ölçek uygulanmış ve iki uygulamaya ait puanlar arasındaki ilişki alt boyutlar ve toplam puan açısından incelenmiştir. Buna göre her iki uygulama arasında toplam puan açısından .75, "alternatifler" alt boyutu açısından .78 ve "kontrol" alt boyutu açısından .73 korelasyon bulunmuştur. Güvenirlik için ayrıca ölçeğin iç tutarlık (Cronbach alfa) güvenirlik katsayısı hesaplanmış ve ölçeğin tümü için .90, "alternatifler" alt boyutu için .90 ve "kontrol" alt boyutu için .84 olarak saptanmıştır. Güvenirlik sonuçları için kabul edilebilir katsayı değerinin $\geq .70$ olduğu göz önünde bulundurulursa (Tavşanc1l, 2002; Özgüven, 1994) elde edilen bu sonuçların BEE' nin yeterli düzeyde güvenirliğe sahip olduğunu gösterdiği söylenebilir.

BEE' nin toplam puan ve alt boyutlarına ilişkin puan ortalamalarının, cinsiyete göre anlamlı bir farklılık gösterip göstermediğini belirlemek amacıyla bağımsız örneklemler $t$ testi yapılmıştır. Buna göre toplam puan açısından erkeklerin bilişsel esneklik düzeyinin kadınlardan anlamlı düzeyde yüksek olduğu saptanmıştır. "Alternatifler" alt boyutu puanları açısından cinsiyete göre istatistiksel olarak anlamlı bir farklılık bulunmamıştır. "Kontrol" alt boyutu puanları açısından kadınların puanlarının erkeklere göre istatistiksel olarak anlamlı düzeyde yüksek olduğu sonucuna ulaşılmışıır.

Sonuç olarak BEE'nin Türk üniversite öğrencilerinin bilişsel esneklik düzeyini ölçebilecek geçerli ve güvenilir bir ölçme aracı olduğu söylenebilir. BEE' yi gerektiğinde psikolojik danışmanlar ve psikoterapistler danışanların bilişsel esneklik düzeyleri hakkında bilgi edinmek amacıyla kullanabilirler. 
Yine araştırmacılar bilişsel esneklikle psikolojik rahatsızlıklar, yaşam doyumu, mutluluk, psikolojik sağlamlık ve psikolojik iyi oluş gibi değişkenler arasındaki ilişkileri araştırabilir, pek çok soruya cevap bulabilirler.

\section{KAYNAKLAR}

Balcı, S. ve Yılmaz, M. (2002). İyimserlik Ölçeğinin Geliştirilmesi: Geçerlik ve Güvenirlik Çalışması. Ondokuz Mayıs Üniversitesi Eğitim Fakültesi Dergisi, 14, 54-60.

Beck, A. T., Rush, A. J., Shaw, B. F. \& Emery, G. (1979). Cognitive Therapy Of Depression. New York: Guilford Press.

Bentler, P. M. (1980). Multivariate analysis with latent variables: Causal modeling. Annual Review of Psychology, 31, 419-456.

Bilgin, M. (2009). Bilişsel Esnekliği Yordayan Bazı Değişkenler. Çukurova Üniversitesi Eğitim Fakültesi Dergisi, 3(36), 142-157.

Boratav, C. (2003). Boratav Depresyon Tarama Ölçeği (Bordepta): Epidemiyolojik Çalışmalar ve Birinci Basamak Sağlık Hizmetinde Depresyonu Tanımaya Duyarlı Bir Ölçek. Türk Psikiyatri Dergisi, 14(3), 172-183.

Browne, M.W. \& Cudeck, R. (1993). Alternative ways of assessing model fit. In K. A. Bollen \& J. S. Long (Eds.), Testing structural equation models. Newbury Park, CA: Sage.

Büyüköztürk, Ş. (2004). Veri Analizi El Kitabı. Ankara: Pegem A Yayıncılık.

Byrne, B. M., \& Campbell, T. L. (1999). Cross-cultural comparisons and the presumption of equivalent measurement and theoretical structure: a look beneath the surface. Journal of Cross Cultural Psychology, 30, 555-574.

Dennis, J. P. \& Wal, J. S. V. (2010). The cognitive flexibility inventory: Instrument development and estimates of reliability and validity. Cognitive Therapy and Research, 34 (3), 241-253.

Hill, A. (2008). "Predictors of relationship satisfaction: The link between cognitive flexibility, compassionate love and level of differentiation." Unpublished doctoral dissertations, California School of Professional Psychology, Alliant International University, San Diego.

Karasar, N. (1995) Bilimsel Araştırma Yöntemi (7. Baskı). Ankara: Sim Matbaası.

Kline, R. B. (2005). Principles and practice of structural equations modeling. New York: Guilford.

Maltby, J., Day, L., McCutcheon, L. E., Martin, M. M. \& Cayanus, J. L. (2004). Celebrity worship, cognitive flexibility and social complexity. Personality and Individual Differences, 37, 1475-1482.

Marsh, H. W., Hau, K.T., Artelt, C., Baumert, J. \& Peschar, J. L. (2006). OECD's brief self-report measure of educational psychology's most useful affective constructs: Cross-cultural, psychometric comparisons across 25 countries. International Journal of Testing, 6(4), 311-360. 
Martin, M. M. \& Rubin, R. B. (1995). A new measure of cognitive flexibility. Psychological Reports, 76 (2), 623-626.

Martin, M. M. \& Anderson, C. M. (1998). The cognitive flexibility scale: Three validity studies. Communication Reports, 11(1), 1-9.

Martin, M. M. \& Rubin, R. B. (1994). Development of communication flexibility scale. Southern Communication Journal, 59, 171-178.

Öner, N. (1997). Türkiye'de Kullanılan Psikolojik Testler: Bir Başvuru Kaynağı (3. Baskı). İstanbul: Boğaziçi Üniversitesi Matbaası.

Özgüven, İ. E. (1994). Psikolojik Testler. Ankara: Yeni Doğuş Matbaası.

Sungur, M. Z. (1994). Kognitif Görüş Bağlamında Depresyon ve Antisipasyon. 3PPsikiyatri, Psikoloji ve Psikofarmakoloji Dergisi, 2 (Ek-4), 5-23.

Şeker, H. ve Gençdoğan, B. (2006). Psikolojide ve Eğitimde Ölçme Aracı Geliştirme. Ankara: Nobel Yayın Dağıtım.

Tavşancıl, E. (2002). Tutumların Ölçülmesi ve Spss İle Veri Analizi. Ankara: Nobel Yayın Dağıtım.

Türkçapar, H.(2009). Klinik Uygulamada Bilişsel-Davranışcı Terapi: Depresyon. Ankara: Hekimler Yayın Birliği.

Young, J. E., Weinberger, A. D. \& Beck, A. T. (2001). Cognitive Therapy For Depression. In D. H. Barlow (Ed.), Clinical Handbook of Psychological Disorders: A Step-By-Step Treatment Manual. New York: Guilford Press. 
